Aletria, Belo Horizonte, v. 31, n. 3, p. 97-118, 2021

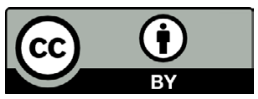

\title{
A literatura trânsfuga de José Falero
}

\section{José Falero's transfuge literature}

\author{
Andrea Cristiane Kahmann \\ Universidade Federal de Pelotas (UFPel), Pelotas, Rio Grande do Sul / Brasil \\ andrea.kahmann@ufpel.edu.br
}

https://orcid.org/0000-0001-8582-9210

Resumo: Este artigo aborda a literatura de José Falero como trânsfuga, ou seja, a que rompe barreiras de expectativas no jogo literário. Afinal, as origens sociais e os círculos de socialização da pessoa que escreve, assim como a profissão que exerce para além da literatura, acabam, frequentemente, por mediar a atribuição de "mérito" à obra. Apesar disso, é nos sistemas relativamente dominados e de agentes sem privilégio no jogo literário que, não raro, surgem as produções mais inovadoras. A partir dessa perspectiva, analiso a literatura de José Falero, sobretudo os contos de Vila Sapo (2019) e o romance Os supridores (2020), além de entrevistas concedidas pelo escritor a jornais, a um podcast e à própria autora deste trabalho.

Palavras-chave: jogo literário, contexto social, habitus e escritura, trânsfuga, José Falero.

Abstract: The purpose of this article is to analyze José Falero's literature as a transfuge, that is, a writing that breaks barriers of expectations in the literary game. After all, the social origin and socialization circles of the person who writes, as well as the profession beyond literature, often end up mediating the attribution of the "merit" of the work. On the other hand, it is in the relatively dominated systems and from the agents without privilege in the literary game that the most innovative productions often emerge. This is the perspective from which we will approach José Falero's literature, for this we use the short stories of "Vila Sapo" (2019) and the novel "Os supridores" (2020), in addition to interviews given by the writer to newspapers, to a podcast and to the author of this work.

Keywords: literary game, social context, habitus and writing, transfuge, José Falero. 


\section{Introdução}

Este trabalho parte da definição de literatura não como um campo autônomo, mas uma arena em que operam também e principalmente mecanismos classificatórios extraliterários, que determinam para escritores/as ${ }^{1}$ hierarquias calcadas em critérios (frequentemente inconfessáveis) que excluem dos círculos de acreditação de prestígio pessoas que se atrevam a furar bloqueios determinados por origens sociais e de socialização. Assim, não apenas se delineia a interiorização de limitações objetivas que afastam determinados grupos da possibilidade de sequer sonhar escrever literatura, como também se impõem obstáculos à publicação e à recepção da obra de quem ouse atravessar barreiras. No Brasil, o $9^{\circ}$ país mais desigual do mundo (IBGE, 2019), os mecanismos de constrangimentos e recompensas, materiais ou simbólicas (e, nesse último caso, tanto mais violentas quanto mais discretas conseguirem ser), é possível observar um perfil prototípico de escritor/a. Esse perfil privilegia o homem branco, residente em determinadas cidades (DALCASTAGNÉ, 2012), e que agrega à escrita literária uma profissão de prestígio (LAHIRE; WELLS, 2010). Bernard Lahire (2012), no entanto, recorda que não são raros os casos de escritas inovadoras surgidas a partir de espaços desprestigiados. Estar alheio às regras do jogo literário, ou seja, escrever do lado de fora do campo institucionalizado, pode favorecer o surgimento de autores/as que, ao menos num primeiro momento, não têm ilusões de consagração no mundo das letras, mas atendem a um compromisso político ou a uma espécie de chamado vocacional. A esses/ as autores/as chamaremos de trânsfugas se forem capazes de migrar entre níveis hierárquicos e de prestígio. Será trânsfuga o movimento que leva o cânone à periferia, ou do contrário, à assimilação pelas redes de (auto) proteção e reverência mútua o/a escritor/a ou a escrita antes invisibilizada por ser periférica. De algum modo, os dois movimentos são observáveis na trajetória de José Falero, a quem dedico este artigo.

\footnotetext{
1 Apesar de que, nos casos de substantivos e adjetivos de dois gêneros, exista a recomendação de repetir masculino e feminino com vistas a conferir mais visibilidade às mulheres e democratizar o acesso ao texto (RIO GRANDE DO SUL, 2014, p. 67), opto pelo uso das barras diagonais por ser este um artigo com limite de palavras e voltado a um público especializado. Faço-o conforme sistematização do manual do Mercosul (2018, p. 14).
} 
Para empreender essa proposta, recorro à revisão de literatura sobre o tema (trânsfuga), à compilação de informações coletadas em entrevistas concedidas pelo autor a jornais impressos e um podcast, além de uma entrevista à autora deste trabalho. Alguns pontos são ilustrados com trechos das seguintes obras do José Falero: o livro de contos Vila Sapo, de 2019, sua estreia em livro impresso sob o selo da editora independente Venas Abiertas, de Porto Alegre; o romance Os supridores, lançado em 2020 pela editora Todavia, de São Paulo, e uma crônica dentre as que ele publica semanalmente na revista digital Parêntese. O objetivo deste trabalho, ademais de contribuir para os estudos sobre trânsfugas, ainda incipientes na academia brasileira (ao menos na área da Literatura), é o de, partindo do caso de José Falero, promover uma reflexão sobre os impactos da (crescente) desigualdade social brasileira na constituição do próprio conceito de escritor/a e escritura, para além da formação de um gosto literário elitista e de temas essencialmente representativos das camadas sociais dominantes.

Há tempos, a sociologia vem-se ocupando de compreender trânsfugas em diferentes campos sociais, como, por exemplo, o do sucesso escolar. Uma pesquisa de Catherine Compton-Lilly acompanhou por dez anos o desenvolvimento de sete crianças de uma escola norteamericana em região de pobreza extrema. Todos os nomes de lugares e pessoas foram substituídos por pseudônimos na publicação de 2014, que se detém da trajetória de Peter, um afro-americano que, durante o desenvolvimento da pesquisa, passou a definir-se como escritor. Segundo Compton-Lilly (2014), Peter não carecia de talento, mas precisava superar obstáculos para acessar o campo - termo empregado conforme o referencial teórico de Pierre Bourdieu. Para o sociólogo francês, a compreensão da gênese social de um campo passaria pela apreensão das crenças que o sustentam, do "jogo de linguagem que nele se joga, das coisas materiais e simbólicas em jogo que nele se geram" (BOURDIEU, 2001a, p. 69). Por meio dessa assimilação das regras do jogo, seria possível antecipar mecanismos de constrangimentos e recompensas que são classificatórios, mesmo que nunca se proponham como tal, e frequentemente são também inconfessáveis. Afinal, segundo ComptonLilly (2014, p. 376): “As práticas, inclusive as práticas de letramento, 
são o resultado de ajustes, adaptações, interações e negociações envolvendo disposições e identidades em relação aos campos em que as pessoas operam". ${ }^{2}$ No entanto, Compton-Lilly (2014) reconhece que, muito mais do que talento, para obter reconhecimento como escritor, Peter precisará compreender as regras do jogo literário.

Jogo, e não campo literário, é a terminologia proposta por Lahire (2012, p. 412), que argumenta que as teorizações de Bourdieu sobre o campo literário explicariam apenas esse microcosmo muito peculiar constituído pela literatura nacional francesa da segunda metade do século XIX, caracterizada por uma situação de mononacionalismo, monolinguismo e posição dominante na geopolítica da cultura. Assim, Lahire (2012, p. 424) pondera que, embora a literatura possa constituir um universo com especificidades, não pode ser tratada como autônoma, pois é, antes de tudo, inseparável da experiência dos/as escritores/as. São as vivências (e os mecanismos manejados) fora do jogo que decidem a partida literária, quando da definição de premiações, competições, busca de honrarias e distinções acadêmicas e semelhantes (que pautam as literaturas hegemônicas, pretensamente autônomas ou depuradas). $\mathrm{Ou}$, como explica Terry Eagleton (2006, p. 24) sobre a literatura:

os juízos de valor que a constituem são historicamente variáveis, mas esses juízos têm, eles próprios, uma estreita relação com as ideologias sociais ( ...) pelos quais certos grupos sociais exercem e mantêm o poder sobre outros.

Reconheço que são as tensões políticas, sociais e ideológicas, e não as regras (depuradas) da arte que explicam o combate "entre os dominantes que pactuam com a continuidade, a identidade, a reprodução, e os dominados, os recém-chegados, que têm interesse na descontinuidade, na ruptura, na diferença, na revolução" (BOURDIEU, 1996, p. 181).

Para a preservação das estruturas de dominação, ferramentais teóricos como a pureza e a autonomia literárias foram sempre muito úteis, como se infere do exemplo de duas revistas literárias surgidas em diferentes continentes e sistemas políticos, mas aproximadas pelo tempo histórico e pelos interesses ocultos sob seus critérios para consagração de obras. A Scrutiny, lançada na Inglaterra em 1932, defendia "atenção

2 Tradução nossa para: "Practices, including literacy practices, are the result of the adjustments, adaptations, interactions, and negotiations involving dispositions and identities in relation to the fields in which people operate". 
disciplinada para com as palavras contidas na página" (EAGLETON, 2006 , p. 48, grifos do autor). Defendia uma arte pura e uma literatura intocada como única forma de elevar os espíritos e preservá-los do industrialismo cultural que só visa ao lucro. Apresentava-se como avessa à solução política, porém, nas obras incensadas pela revista, "as pessoas comuns só pareciam aceitáveis se fossem pastores do século XVII, ou campônios australianos cheios de vida" (EAGLETON, 2006, p. 53, grifos do autor). A função ideológica da Scrutiny era essencialmente a de resguardar o jogo das letras às pessoas que haviam estudado nos colégios aristocráticos e com acesso pavimentado aos restritos círculos da nobreza inglesa. De Buenos Aires, o exemplo da revista Sur, fundada por Victoria Ocampo em 1931, é evocado por Sergio Miceli (2018). Sur ignorou sistematicamente escritores/as como Roberto Arlt, Horacio Quiroga e Alfonsina Storni, de famílias brancas, mas pobres e imigrantes, que inflacionavam as disputas por espaços nas universidades e profissões liberais, desestabilizando os privilégios das elites criollas. Estas sentiam pertencer-lhes, por tradição, a legitimação dos capitais e dos bens simbólicos e, por isso, clamariam pela "arte pela arte" tanto quanto pela "segunda pele do privilégio por merecimento" (MICELI, 2018, p. 79).

Apesar desses esforços por constranger intrusos/as do jogo literário, Lahire (2012, p. 413) recorda que os espaços literários mais institucionalizados, mesmo em áreas de vanguarda, nem sempre favorecem o surgimento de obras inovadoras. Não são incomuns os casos de escritores/as que constroem seu trabalho a partir de espaços relativamente dominados valendo-se de experiências ou de compromissos políticos evidentes. Escrever a partir de um espaço desprestigiado pode ser favorável ao surgimento de autores/as que, ao menos num primeiro momento, não têm ilusões de consagração no mundo das letras, mas que escrevem como se atendessem a uma espécie de chamado vocacional.

Esse pode ter sido o caso de Peter, o sujeito da pesquisa de Compton-Lilly (2014) referido por um pseudônimo, e é, com efeito, o caso de José Carlos da Silva Junior, o nome real do escritor que assina com o pseudônimo de José Falero, o sujeito em que se passa a deter o presente artigo.

Nascido em 1987, em Porto Alegre, José Falero lançou-se como escritor nas redes sociais. Depois, participou de duas coletâneas: $\grave{A}$ margem da sanidade (J. Vellucy, 2018) e Ancestralidades: escritores 
negros (Venas Abiertas, 2019). É autor de duas obras de autoria única: a coletânea de contos Vila Sapo (Venas Abiertas, 2019) e o romance $O s$ supridores (Todavia, 2020). Este romance, sucesso de crítica na imprensa cultural brasileira, está atualmente sendo traduzido para o francês e o inglês (SPERB, 2021).

Afirmar que José Falero é um trânsfuga por ter-se formado como escritor na capital gaúcha tem todo aspecto de uma incoerência. Porto Alegre é pródiga em lançar romancistas; afinal, é sede do mais tradicional curso de escrita criativa em ambiente acadêmico do Brasil (o da PUCRS, desde 1985) e a única cidade brasileira a ter duas universidades com Programas de Pós-Graduação em Letras com nota máxima na Capes, ambas com abertura à escrita criativa. ${ }^{3}$ Conforme levantamento de Regina Dalcastagné divulgado na revista Cult (MASSUELA, 2018), o perfil do romancista brasileiro publicado por grandes editoras é de pessoas que "vivem basicamente no Rio de Janeiro (33\%), São Paulo (27\%) e Rio Grande do Sul (9\%)". Se os dados se referissem não à moradia, mas às cidades de nascimento ou aos círculos de socialização dos/as romancistas, o percentual seria engrossado pelo cômputo, entre muitos/as outros/as, dos porto-alegrenses Michel Laub e Paulo Scott, e também Daniel Pellizzari e Daniel Galera. Os dois últimos não nasceram na capital gaúcha, mas nela cresceram e se forjaram escritores com certa popularidade. ${ }^{4}$ José Falero, no entanto, difere-se desse perfil. Embora seja nascido e criado em Porto Alegre, ele não vem da cidade pela qual circulam os/as escritores/as. Porto Alegre, como todo espaço urbano brasileiro, pode ser muitas.

São as águas pardas do estuário do Guaíba, chamado de rio pelos/ as porto-alegrenses, que separam a Vila Assunção, com seu IDHM (Índice de Desenvolvimento Humano Municipal) de 0,953, das Ilhas do Pavão e dos Marinheiros, com IDHM de 0,593, conforme dados de 2010 (apud FERREIRA; MENEZES, 2017, p. 30). No outro extremo da cidade, bem longe do rio, com seu vasto território e contingente populacional,

${ }^{3}$ O Programa de Pós-Graduação em Letras da PUCRS tem área de concentração em Escrita Criativa, e o da UFRGS apresenta a linha de pesquisa Estudos literários aplicados: Literatura, Ensino e Escrita criativa.

${ }_{4}$ A relativa popularidade de Daniel Pellizzari e Daniel Galera teve início com o Cardosonline (COL), um mail-zine (fanzine distribuído via e-mail) que formou gostos literários até 2001, ano em que fundaram a editora independente Livros do mal. Essa editora perdurou até 2004; depois, ambos passaram a dedicar-se a jogos mais hegemônicos em editoras grandes do centro do país. 
a Lomba do Pinheiro ostenta IDHM de 0,683. Ela é descrita na ficção (mas bem poderia ser num estudo acadêmico) como "afastada do Centro, fora do alcance dos tentáculos do poder público, abandonada à própria sorte" (FALERO, 2020b, p. 18). Se esses bairros fossem países, conforme tabela do PNUD (dados de 2014), a Vila Assunção estaria no topo do ranking mundial, acima até mesmo da Noruega $(0,944)$; já a Lomba do Pinheiro, ficaria um pouco atrás do Gabão $(0,684)$.

Assim como os seus protagonistas, José Falero é justamente dali, da Vila Sapo, um lugar não mapeado da vasta Lomba do Pinheiro. Falero apresenta-se assim mesmo: "eu sou”, e não "eu moro" na Lomba do Pinheiro. Isso faz recordar Néstor García Canclini (2003, p. 159) e sua ponderação de que os shoppings centers (e, com eles, as megassalas de cinemas e livrarias megastores, que vendem a ilusão de fruição dos mesmos produtos de indústria cultural que outras partes do mundo) trazem aos estratos sociais acomodados não só a ilusão de segurança e higiene, mas também a de pertencer a um fenômeno global. Assim, enquanto residentes de áreas modernas dizem "morar em", nas áreas mais populares das cidades responde-se "sou de", pois há o sentimento de que "pertencem" àquele lugar (e talvez somente a ele).

Além do fato de ser de, e não apenas morar na periferia, José Falero distingue-se do perfil prototípico de um/a romancista, conforme Regina Dalcastagné (2012), por ser negro claro e não exercer nenhuma profissão de prestígio. Os campos sociais em que geralmente se constituem as segundas vidas de escritores/as foram teorizados por Bernard Lahire e Gwendolyn Wells (2010), que analisam a manutenção social da imagem de escritores/as paralelamente ao "day job [trabalho diurno]" (2010, p. 445) que, por razões, em geral, econômicas, precisam desempenhar. Esses diferentes campos sociais pelos que transitam escritores/as em suas segundas vidas acarretariam diferentes backgrounds, a implicar (des)favorecimentos (dentro e fora) do jogo literário. Alinhavando essas reflexões com a realidade brasileira perfilada por Dalcastagné (2012), é possível postular que, no Brasil, uma prova robusta da heteronomia do jogo literário encontra-se sob a fórmula "escritor/a $e$ [profissão de prestígio]", frequente nas apresentações de escritores/as famosos/as. A profissão que complementa a fórmula pode repousar na advocacia, na medicina ou em 
profissões não regulamentadas,como a de jornalista e tradutor/a. ${ }^{5}$ Retomo, apenas para exemplificar a formulação, os quatro citados escritores de prestígio também formados em Porto Alegre e publicados por editoras do centro. São pequenas as variações entre suas segundas vidas apresentadas no site da Companhia das Letras (2021), editora que os congrega: Michel Laub é "escritor e jornalista"; Daniel Galera, "[e]scritor e tradutor de literatura contemporânea de língua inglesa" - embora o Wikipedia (2021b) denuncie-o como publicitário; Paulo Scott é "escritor e professor universitário", formado em Direito, conforme a Wikipedia (2021c); e Daniel Pellizzari teria "vida tripla": "escritor, tradutor e editor" - não foram encontradas informações confiáveis sobre sua formação em graduação. Quando, porém, procuro o site da editora Todavia (2021) para verificar como é ali apresentado o seu romancista estreante, encontro apenas: "José Falero nasceu em 1987, em Porto Alegre. Estreou, em 2019, com VILA SAPO, elogiada reunião de contos. Mantém uma crônica semanal na revista digital Parêntese". A palavra escritor é a ausência que grita nessa apresentação: é como se ela não parasse em pé sozinha, é como se não pudesse existir senão antecedendo uma profissão de prestígio. ${ }^{6}$

Na revista Parêntese, José Falero (2020a) apresenta-se como alguém que: "[t]rabalha como auxiliar de gesseiro para não morrer de

\footnotetext{
5 A obrigatoriedade da formação superior específica para o exercício do jornalismo (conforme previsto pelo Decreto-Lei 972/69) foi modificada por decisão do Supremo Tribunal Federal de 2009. Já a atividade de tradutor/a, apesar de inserida em campo acadêmico bem estabelecido desde 1970, nunca alcançou regulamentação. Podem provir disso os diferentes usos sociais das palavras "jornalista" e "tradutor/a" no Brasil. Se, embora seja raro ver alguém apresentar-se como "jornalista", ainda que escreva em jornal (como é o caso de José Falero), não existem constrangimentos em apresentar-se como "tradutor/a" qualquer pessoa que realize traduções, mesmo sem formação na área. 6 Para escamotear dúvidas de que a fórmula "escritor e [profissão de prestígio]" fosse empregada também pela editora Todavia, analisei o seu catálogo de autores/as, que conformaria um interessante corpus para análise dos usos sociais possíveis aos discursos formulados entre ser escritor/a e ser autor/a. Exemplifico transcrevendo apresentações: "Daniel Sada foi um poeta, jornalista e escritor mexicano" [deduz-se: poeta não é escritor]; "Andrés Barba nasceu em Madri, em 1975. Ficcionista, poeta, ensaísta, fotógrafo e autor de livros infantis (....)," [deduz-se: escrever livros infantis não é ficcionalizar]. Ademais, a palavra escritor/a não é estendida a qualquer pessoa que tenha publicado livros. O próprio Andrés Barba, quando muito, é apenas "ficcionista, poeta, ensaísta e autor de livros infantis”. Já Daniel Sada parece ter sido alçado ao título por reunir à fórmula a condição de jornalista, do mesmo modo que "Domenico Starnone é um escritor, roteirista e jornalista italiano" e "James Bridle nasceu em 1980, no Reino Unido. É escritor, jornalista e artista visual". (Conforme: <https://todavialivros.com. br/autores> Acesso em: 28 jan. 2021).
} 
fome, e toca cavaquinho para não morrer de tristeza". Apesar de escrever também reportagens para a equipe do Matinal Jornalismo, de que faz parte a revista Parêntese, Falero não se habilita à apresentação como jornalista. Seu principal vínculo com assinantes do portal são as crônicas semanais com tom autobiográfico. No podcast da Clandestina (2020), Falero foi questionado sobre essa experiência da escrita de si. Transcrevo sua resposta:

\begin{abstract}
(...) é a ideia da crônica, ao meu ver, assim, eu posso tá dizendo besteira, mas... é uma coisa assim mais em relação ao tempo de agora (...) mesmo que uma crônica traga uma reflexão de tempos passados, mas é o que esse José de hoje reflete sobre aquele evento, sabe? Enfim... (...) eu fui pegando a manha aos poucos, fui amadurecendo... nem sei se aprendi [ri]... é um processo, né, que eu tô ainda tentando aprender. (CLANDESTINA, 2020)
\end{abstract}

Falero é humilde com relação ao domínio dos gêneros e formas narrativas. Ao contrário da maioria de autores/as de prestígio lançados em Porto Alegre, ele não estudou na PUC (conforme PUCRS, 2020). Falero é estudante de EJA (Educação de Jovens e Adultos) e todo o período em que frequentou a universidade foi como ajudante de pedreiro numa espécie de galpão construído no Campus do Vale da UFRGS. Essa experiência é relatada na crônica "De volta ao campus": "Quando o galpão finalmente ficou pronto, eu dei graças a Deus. Creia-me, leitor: não existe ambiente mais hostil para um pé-rapado do que um ambiente acadêmico" (FALERO, 2020a). Na entrevista que faço com José Falero, pergunto se ele ainda se sente assim em relação ao campus; ele explica que esse da crônica é o José do passado. Na sequência da mesma crônica, ele narra (e me confirma na entrevista que o evento é verídico) seu retorno ao campus da UFRGS para assistir a um curso sobre Literatura MarginalPeriférica com Érica Peçanha: "Eu tinha propriedade para falar de tudo aquilo. Não me atrevi a abrir a boca, mas que eu tinha propriedade, ah, isso eu tinha! E me bastou" (FALERO, 2020a). Além disso, "[e]ra de graça, então cabia direitinho dentro do meu orçamento" (FALERO, 2020a).

Ao contrário de Peter, o sujeito da pesquisa de Compton-Lilly (2014), não foi na escola que José Falero descobriu-se escritor. Questiono-o sobre uma reportagem publicada na GZH (LUCCHESE, 2020), em que sua foto aparece junto à afirmação: "Se dependesse das instituições formais, eu jamais me tornaria um leitor". Falero (2021) me responde que "não é hora" de criticar a educação, mas é preciso pensar no assunto. À mesma reportagem de $\mathrm{GZH}$, ele relata que começou a ler por influência da irmã 
mais velha: "Um dia ela me disse que minha opinião sobre um assunto não valia nada, pois eu nunca tinha lido um livro. Fiquei com aquilo na cabeça. Peguei um livro emprestado. Era sobre lobisomens. E nunca mais parei de ler" (LUCCHESE, 2020). Autodidata, ele passa a devorar livros e, por meio deles, assimila as regras da arte literária.

Pela entrevista que Falero me concede, percebo que é nas mulheres de sua família, a mãe e a irmã, primeiro, e a namorada Dalva, mais recentemente, que ele encontra suas referências e seu principal incentivo. Seu primeiro livro, Vila Sapo (FALERO, 2019), traz a dedicatória: "Para Rita, para Caroline, para Dalva. Com amor e gratidão". Já na nota "sobre o autor", ao final do livro, consta que ele "[a]dotou o pseudônimo "José Falero" em homenagem à mãe, de quem herdou a veia artística, mas não o sobrenome". Pergunto-lhe, então, qual é a veia artística da mãe, Rita Helena, ao que ele responde que ela fez magistério e caprichava nos desenhos para atividades com estudantes:

Ela desenhava muito e em algum momento parou de desenhar (...). Eu tenho pra mim que minha mãe é uma artista reprimida, sabe? Enfim, o que não falta por aí é isso, né? Eu tenho pra mim que a minha mãe é uma pessoa a quem não foi dado o direito de potencializar essa veia, essa expressão, né? E eu acho que um dos sintomas, dos indícios disso, além dessas coisas que eu falei, é que ela sempre fez de tudo para apoiar os meus projetos artísticos e os da minha irmã. (FALERO, 2021)

Quando José decide ser escritor, a mãe torna-se sua primeira leitora. O papel central de Rita Helena Falero no desenvolvimento das ambições e condições artísticas do filho rompe com o que Lahire (2011) designa A transmissão familiar da ordem desigual das coisas, que poderia ser sintetizada em expressões como "Isto não é para nós" (LAHIRE, 2011, p. 14). Para Lahire (2011), a interiorização de limitações objetivas no seio das famílias tende a forjar a construção irrefletida de que aquilo "que não é objectivamente acessível não passa a ser subjectivamente desejável e acabamos por gostar apenas do que a situação objectiva nos permite gostar" (LAHIRE, 2011, p. 14). Ademais:

É também através de mecanismos de manutenção da dignidade ("eu não posso - sem decepcionar todos os que estão à minha volta - visar menos do que...") ou de antecipação da possível denúncia das pretensões ("eles vão perguntar por quem eu me julgo"), que as expectativas subjectivas se estabilizam, ao mesmo tempo que as desigualdades se perpetuam (LAHIRE, 2011, p. 15). 
Mas, ao fim e a cabo, diz Lahire (2011, p. 15), "a família nunca é este organismo coerente, homogéneo e harmonioso como nas visões encantadas". Mesmo com essa ponderação, é preciso estabelecer uma crítica: essa abordagem de Lahire (2011) sobre a transmissão da desigualdade restringindo-a às expectativas familiares devem ser analisadas com extrema cautela em face da realidade social deste que já é o $9^{\circ}$ país mais desigual do mundo (IBGE, 2019). A história familiar de Falero demonstra que, para muito além do incentivo familiar, romper a transmissão da ordem desigual das coisas requer condições materiais objetivas e atuação decidida do Estado no provimento de escolas públicas e professoras/es capazes de pavimentar o acesso a livros, artes e sonhos. Porque, se não, acontece na vida real o mesmo que se passa na ficção de Falero (2020b, p. 83-84):

Uma criança de família pobre, pensava, tinha tantos sonhos quanto uma criança de família rica, mas, ao contrário desta, ia sepultandoos um a um ao longo dos anos, conforme ia amadurecendo e percebendo que apenas fazer por onde não passar fome já era uma tarefa bastante difícil, que a luta constante para não cruzar a fronteira da sua classe social com a dos mendigos já era árdua e desgastante.

Da irmã quatro anos mais velha, Caroline, José Falero me conta: "eu tenho ela como referência mesmo antes de ela ser artista assim, sabe?" (FALERO, 2021). Quando Caroline vai cursar Pedagogia da Arte na Universidade Estadual do Rio Grande do Sul (UERGS), torna-se, aos olhos do caçula, "a artista da família" (FALERO, 2021). "Eu via ela como referência porque eu tinha a impressão que ela era super firme: ela tinha presença, postura, se impunha, né? Aí, eu cresci vendo isso e pensei 'poxa, eu quero ser assim', sabe?" (FALERO, 2021). Eu não pergunto, mas ele talvez adivinhe minha ansiedade por descobrir o que o impedira de chegar à universidade, tal como a irmã. Então, explica-me, com outras palavras, que a "natureza" dessa ordem desigual das coisas nasce da desigualdade social porto-alegrense:

É que, tipo assim, a gente era quatro, né? Eu, minha irmã, minha mãe e meu pai. Aí a gente tava no Pinheiro e tal e a gente foi morar... tô trazendo aqui a natureza dessas questões, né? A gente foi morar na Cidade Baixa [bairro conhecido por boêmio e universitário, próximo ao centro administrativo e comercial de Porto Alegre]. Imagina o choque, né? A gente foi morar na Cidade Baixa porque meu pai virou zelador lá. Aí, depois de um tempo, ele se separou da minha mãe, né? Meu pai é falecido, um pouco antes de falecer, 
ele se separou da minha mãe. E a minha mãe voltou a morar na Lomba do Pinheiro, e eu voltei com a minha mãe. A minha irmã ficou morando com meu pai, porque a minha irmã tava estudando num bom colégio na época, fazendo o ensino médio lá no Parobé. Aí eu tava no ensino fundamental, meio que tanto fazia o colégio, e então ok, vou vim com minha mãe. E ela não, né? Ela ficou lá. Ela fazia um curso de Eletrônica, se eu não me engano, no Parobé, que era feito junto com o Ensino Médio, e por essas questões ela ficou lá no meu pai. Aí é nesse curso que ela vai conhecer o pessoal do teatro, vai começar a frequentar teatro, vai se apaixonar por teatro, e mais: vai ter contato com essa possibilidade do mundo acadêmico. E eu, aqui no Pinheiro, vim me desenvolver numa outra realidade, numa realidade em que ninguém sonha em cursar uma graduação, onde é meio que... ninguém sequer conversa sobre isso. É meio que assim ó: olha, tu vai acabar o ensino fundamental e tu vai começar a trabalhar, sabe? É o senso comum generalizado, assim. Todo mundo pensa isso. Acabou o ensino fundamental, é trabalho. Se tu quiser, tu ainda faz o médio, pra tentar conseguir uns trabalhos depois, mas é trabalhar e fazer o ensino médio ao mesmo tempo. Ou abandona o estudo. Mas é isso: concluir o ensino médio é o topo, assim. (FALERO, 2021)

As diferenças na socialização escolar de José Carlos e Caroline fazem recordar o estudo de Compton-Lilly (2014) sobre Peter, um estudante destaque em notas e comportamento ao longo de toda a pesquisa. Nos desenhos de Peter, a escola é retratada como um ambiente em que ele e seus amigos riem. Peter cresce com fortes alianças emocionais com a escola, amigos/as da escola e professores/as. E, sob a perspectiva de seu irmão mais novo, Caroline seria também uma trânsfuga do sucesso escolar: cumprindo expectativas apr(e)endidas na boa escola em que estudou, ela rompe com o que era [relativamente] esperado para alguém que se muda àquele bairro por ser filha de um zelador. Embora ambas sejam públicas e na mesma cidade, a escola de Caroline definitivamente não é a mesma que o caçula conhece na Lomba do Pinheiro. Por isso, ela, que avança nos estudos, passa a ser o farol do irmão que abandona a escola: "A minha irmã vai me introduzir não só nessa questão artística, mas intelectual mesmo, de como ver as questões do mundo, nos próprios conceitos marxistas" (FALERO, 2021).

Assim, se Lahire (2012), ao refutar a estruturação do conceito de campo literário, ataca também o de habitus, parece irrefutável que, 
ao menos neste Brasil de extremos, existe, sim, um habitus que é apreendido socialmente, embora possa não ser imanente ao campo literário.

Habitus é uma construção do referencial de Bourdieu de dificilíssima conceituação. Pode-se tentar apresentá-la da seguinte forma:

O habitus preenche uma função que, em uma outra filosofia, confiamos à consciência transcendental: é um corpo socializado, um corpo estruturado, um corpo que incorporou as estruturas imanentes de um mundo ou setor particular desse mundo, de um campo, e que estrutura tanto a percepção desse mundo como a ação nesse mundo. (...) É a experiência dóxica pela qual atribuímos ao mundo uma crença mais profunda do que todas as crenças (no sentido comum) já que ela não se pensa como crença. (BOURDIEU, 2001b, p. 144)

O habitus pode ser ilustrado pela autoconfiança adquirida por Caroline, que é percebida pelo irmão como alguém com postura, com presença, para o que, certamente, devem ter contribuído a convivência com os grupos sociais e sobretudo com as expectativas providas por sua escola de prestígio, ainda que pública. Caroline parece, pela descrição do caçula, ter assimilado as regras do jogo social, de modo a portar-se no mundo como alguém capaz de antecipar as jogadas de demais jogadores/ as. Com relação a José, restou-lhe a condição de espectador de outro jogo, o da periferia, onde a mão do Estado não chega do mesmo modo que no centro: as escolas públicas não são as mesmas, o transporte público não é o mesmo, a polícia não é a mesma, as crenças, as ambições, os falares, as percepções e as ações das pessoas não são as mesmas. Mas, conhecedor das expectativas do centro, e por transitar entre os contrastes de dois mundos, Falero propôs-se a traduzir as diferentes realidades, desacomodando, desse modo, visões de classe por meio de temáticas e modos de experimentar a linguagem completamente inovadoras para quem aborda literatura desde a ótica do centro.

Retomando os postulados de Lahire e Wells (2010), de que a experiência é condição fundamental da literatura, é possível concluir que as similitudes entre as segundas vidas de escritores/as e de suas 
narrativas possíveis, conforme a perspectiva dos espaços de socialização que ocupam, constituíam uma relevante lacuna a ser preenchida.

Portanto, não espanta que, após a publicação de Vila Sapo, críticos/ as como Juremir Machado da Silva tenham apregoado: "Falero tem tudo para se tornar um dos grandes escritores brasileiros, se não for preterido por ser negro, pobre e periférico" (SILVA, 2019). As inovações éticas e estéticas de sua narrativa são exaltadas: "A vida real salta em cada palavra. Há uma estranha poesia nessa literatura sem enfeites. (...) Faz a literaturinha de apartamento ficar roxa de vergonha e de inveja" (SILVA, 2019).

$\mathrm{Na}$ condição de mulher branca e "de apartamento", julgo-me incapaz de avaliar o quanto de vida real pulula na escrita de José Falero, mas me associo ao arrebato do colunista em face das inovações temáticas e às experimentações de linguagem que Falero propõe. Juremir fala do livro de contos, mas bem poderia ter sido do romance Os supridores, que dá sequência ao laboratório de experimentação das oscilações entre os discursos de narração e os diálogos. Ademais, tanto numa obra quanto na outra, são frequentes as intervenções de narração para traçar uma explicação a quem lê. Essas intervenções, muitas vezes irônicas, evidenciam "um viés machadiano", segundo Alcir Pécora (2020). Exemplifico:

A tecnologia é como uma atleta jovem e incansável correndo livre e desimpedida (...); a humanidade, coitada, não passa de uma senhora aposentada e enferma da qual ninguém mais quer saber (...). Não sou um tolo. Sei bem que que mesmo naquela época mais amena o tropeção [da humanidade] que presenciei já não poderia ser classificado como evento extraordinário. Entretanto, peço ao leitor que não minimize a gravidade do ocorrido. Lembre-se de que tomar conhecimento da tragédia através do telejornal, ou por meio de um texto como este, é muito diferente de testemunhá-la. (FALERO, 2019, pp. 80 - 81, destaque nosso)

Entre esse narrador elegante do conto "Rosa-bebê" e o narrador debochado de "Atotô", outro conto de Vila Sapo, há um mundo de diferença estilística; não obstante, o recurso narrativo é o mesmo:

Agora, se parece fácil pra tu que tá lendo isto aqui imaginar que a saraivada teve alguma coisa a ver com os três malandro que descero da Vilinha e foro lá pros lado da Viçosa, beleza, palmas pra tu. Mas eu, o Nego Bota Fé e o Nego Tiriça nem pensemo nisso na hora. Não pensemo, porque já tamo acostumado com saraivada. A gente cresceu ouvindo uma pá de saraivada. (FALERO, 2019, p. 29, destaque nosso) 
O narrador de Os supridores assume a mesma tarefa de explicar a quem lê o texto o que se passa na cena, ainda que, às vezes, com mais sutileza, mas não menos ironia:

Evidentemente, a história da promoção a chefe da loja não passava de conversa para boi dormir: uma notícia falsa dada da maneira mais deslavada pelo filho, e recebida como verídica da maneira mais inocente pela mãe. Mas, afinal, quando foi que brotou alguma felicidade, por menor que fosse, num coração conhecedor dos fatos em toda sua profundeza? Quando foi que houve alegria, senão alimentada por completas mentiras ou verdades desfalcadas? Sempre que a realidade mete o pé na porta, não há sorriso que não trate de escapulir pela janela. Todo felizardo é, antes de mais nada, um iludido. (FALERO, 2020b, p. 161)

Por recursos como este, na manchete de Paula Sperb (2021) para a Folha de São Paulo, lê-se: "Renascentista da quebrada, José Falero faz literatura que vai de Machado a Tarantino".

Já Fernando Ramos, no podcast da Clandestina (2020), vê algo de quixotesco em Pedro e Marques, os dois supridores de prateleiras de um supermercado que decidem vender maconha pros playboy, porque esse é único jeito de prover algum conforto para a família e conquistar alguma dignidade. Na narrativa de Falero, os personagens decidem vender só maconha, porque "a erva não era vista como droga por quase ninguém. (...) Droga, droga mesmo, era de cocaína para cima" (2020b, p. 25). Além do mais, a maconha está em falta, ela é "volumosa" (FALERO, 2020b, p. 95), e já não interessa aos traficantes que se concentram no pó e nas britas (o crack), mais lucrativos. Pedro opina que vender maconha vai ser sossegado: "A gente vai evitar conflito, Marques. Tendeu? E é por isso que a gente vai vender só maconha. Ninguém faz guerra por causa de maconha, mano" (FALERO, 2020b, p. 66). A obra se encerra em um faroeste épico pela Vila Planetário, um gueto de extrema pobreza em meio a bairros tradicionais de Porto Alegre, e com a prisão de Pedro.

Embora o final não seja feliz para o protagonista, pode-se dizer que o é para a literatura brasileira, pois Os supridores preenche, sob a ótica da periferia, um problema social que a literatura contemporânea tende a registrar apenas sob a experiência da classe média. Um exemplo está nos personagens ociosos "durante uma das greves da universidade federal, que os deixou sem absolutamente nada para fazer" (GALERA, 2016, p. 44) e que decidem escrever 
contos pornográficos, poemas de verso livre cheios de links apontando pra bizarrices da internet, resenhas de filmes e discos e uma profusão de manifestos artísticos produzidos à base de maconha, LSD, ócio e leituras sui generis dos pós-estruturalistas. (GALERA, 2016, p. 44)

O romance $O$ s supridores, a seu turno, traça a ascensão e a queda da jornada periférica, de gente "[p] obre demais para ser lembrada, preta demais para ser levada em consideração" (FALERO, 2020b, p. 246) e que pode ser "exterminada de maneira tão brutal, mesmo assassinada à luz do dia, mesmo estraçalhada a céu aberto, mesmo aniquilada diante de quem quisesse ver" (FALERO, 2020b, p. 246) porque ninguém se importa. E os supridores jamais estão ociosos e nem sequer cogitam frequentar a universidade. Na contrastante visão de Pedro a Marques: "Imagina tu na facul; só tem burguês na facul, tá ligado?" (FALERO, 2020b, p. 179). As lutas para crescer por meio de estudos e trabalho parecem, com efeito, quixotescas sob a ótica de Pedro:

Afinal, se as pessoa que tão jogando dinheiro pra cima merece tudo que têm, então tu, que não tem porra nenhuma, merece não ter porra nenhuma. E essa lógica simplista faz tu te sentir um fracassado. Isso coloca nos teus ombro um peso foda de aguentar. (...) Eu te mostro que tu não é o vilão da tua própria história. Eu te mostro que, enquanto tu faz força pra subir, tem uma pá de safado fazendo força pra tu ficar onde tu tá, pra tu morrer afogado na merda, porque tu tem que ficar na merda pra eles nunca cair na merda. (FALERO, 2020b, p. 58)

Em Os supridores, a política transborda a cada diálogo, a cada descrição das rotinas e do entorno dos personagens. Eles não precisam ser levados pelo autor às manifestações, onde lhes acende "a vontade de também incendiar algo, ou roubar o revólver do coldre de um policial, só para peitar as consequências" (GALERA, 2016, p. 98). O cenário de Meia noite e vinte, de Daniel Galera, é a mesma Porto Alegre de $O s$ supridores, e são poucas esquinas as que separam os eventos descritos em cada romance. Mas como poderiam os protagonistas deste peitar a polícia? Eles sequer podem ficar no parque, "[p]orque a gente tem a cara e o estilo que os porco tudo tá à cata" (FALERO, 2020b, p. 174).

É essa inovação temática, de estilo e de experiência que parece fechar o circuito da literatura brasileira, trazendo a ela uma mirada 
do outro lado. Por mais que se possa argumentar que a literatura contemporânea venha retomando os ares de romance social (e obras como Marrom e Amarelo, de Paulo Scott, e $O$ avesso da pele, de Jeferson Tenório, ambientadas na mesma Porto Alegre, sejam exemplos bastante contundentes nesse sentido), existe uma carência pulsante dessa literatura que apenas um/a trânsfuga pode gerar. É uma literatura de compromisso político, quase que a traduzir uma classe social para a outra. Evidenciando os contrastes entre as linguagens e as esquinas da cidade, segundo a ótica de quem é autorizado a transgredir ou quem, não importa o que fizer, será visto como bandido, José Falero funde cânone e literatura marginal, e inova mais que qualquer vanguarda. É um escritor autodidata que apreende das regras do jogo apenas o que a (boa) literatura tem a ensinar. A palavra escritor, assim, aprende a parar de pé sozinha, sem precisar de uma profissão de prestígio que a acompanhe.

\section{Considerações finais}

Este trabalho propôs apresentar, sob um referencial sociológico, calcado principalmente nas contribuições teóricas de Lahire (2011 e 2012) e Lahire e Wells (2010), em estreito diálogo com Bourdieu (1996, 2001a e 2001b), o escritor José Falero, descrevendo brevemente suas origens familiares e de socialização para relacionar o escritor e suas obras publicadas à perspectiva trânsfuga. A partir deste caso específico e das reflexões apresentadas com base nele ao longo deste texto, traço algumas conclusões.

A primeira, e mais óbvia, é que as cidades são múltiplas e precisam ser compreendidas em consonância com os alertas que os estudos de sociologia estão constantemente a prover. Uma análise sobre lugares que formam escritores/as e a partir dos quais eles/as escrevem pode induzir conclusões ingênuas. José Falero (e as experiências que impulsionam sua criação literária) está mais próximo da periferia de qualquer grande cidade brasileira (e quiçá do mundo) do que da Porto Alegre capaz de formar escritores/as por meio de ambientes fortemente institucionalizados, como o acadêmico. No entanto, a trajetória de Falero não se desvincula totalmente desses ambientes, pois eles permitiram, ainda que de forma eventual e carregada de violências simbólicas, o acesso do escritor a debates (como o promovido por Érica Peçanha do Nascimento no campus da UFRGS) e a algum reconhecimento. Entendo como reconhecimento as críticas favoráveis a Vila Sapo, publicadas em jornais locais, que abrem as portas 
à escritura de crônicas numa revista digital que, por sua vez, serve de vitrine à editora Todavia, que acaba por publicar um romance (engavetado) do autor e posteriormente negociar direitos de tradução com editoras estrangeiras, transformando em universal o que nasce periférico. Ademais, é preciso mencionar que os ambientes institucionalizados exercem sobre José Falero uma influência indireta, por meio da irmã Caroline, quem apreende habitus e técnicas de criação justamente por meio de instituições educacionais existentes nesta cidade que, lamentavelmente, não é para todos/as. Disso se depreende a importância de políticas de descentralização da cultura, de fortalecimento das instituições públicas e de acesso ao público amplo, como bibliotecas e espaços para oficinas de criação, exposições e trocas comunitárias, que serão tanto mais exitosas quanto mais livres de constrangimentos simbólicos se possam configurar. É possível depreender, também, que sem a ampliação dos acessos a instituições públicas de ensino que sejam capazes de ensinar a aprender e mediar as transposições de bloqueios (em sentido amplo), não existirão trânsfugas do sucesso escolar como Peter, o sujeito da pesquisa de Compton-Lilly (2014), e Caroline, a irmã de José Falero.

A literatura de José Falero serve, neste trabalho, como uma exemplificação da teorização de Lahire (2012), a postular que, com frequência, obras inovadoras surgem não dos ambientes institucionalizados, ainda que de vanguarda, mas dos espaços relativamente desprestigiados. No entanto, com base nos exemplos das revistas Scrutiny (EAGLETON, 2006), e Sur (MICELI, 2018), é preciso reconhecer que construtos como o da autonomia do campo literário privilegiam a (auto)preservação de elites (no sentido econômico, não cultural) na centralidade do campo de forças. É necessário, pois, revelar o quanto há de político, social e ideológico no incensamento de certas/os autoras/es e na invisibilização de outras/os. E essa é uma tarefa que precisa ser assumida pela academia, pois é intransferível a qualquer outro âmbito, ao menos com a impessoalidade que o assunto exige.

Muitas questões não puderam ser suficientemente desenvolvidas e ficam como recomendações a trabalhos futuros. Seria fundamental, por exemplo, uma análise dos papeis que jogam editoras independentes, como a Venas Abiertas (que lança a primeira obra de José Falero) no arejamento da literatura. O desvelamento dos mecanismos de consagração / invisibilização de escritores/as por meio de análises de suas trajetórias pode contribuir para a elucidar critérios inconfessáveis que legitimam algumas pessoas, e não outras, no acesso ao jogo literário. Relações de parentesco, 
de compadrio, apadrinhamento ou, como diz Miceli, "das cifras capazes de deslindar enigmas compartilhados no círculo de sociabilidade" (2018, p. 79) ou de "liquidez financeira, bem maior (...) do que as margens de respiro intelectual e político" (2018, p. 43) podem-se revelar. Por fim, e para além dos Estudos de Literatura, uma análise de discurso que tenha por corpus as apresentações de escritores/as pelas suas editoras é tema ainda à espera de pesquisas. Qual é a diferença, afinal, entre autor/a e escritor/a? Será a constituição da fórmula seguida por profissão de prestígio? E quem é socialmente legitimado/a, no fim das contas, a apresentar-se como profissão não regulamentada por lei, no Brasil? Análises sobre os usos sociais das profissões de jornalista e tradutor/a, por exemplo, podem acarretar preciosas contribuições ao campo de Letras.

\section{Referências}

BOURDIEU, Pierre. A génese dos conceitos de habitus e de campo. In: BOURDIEU, Pierre. O poder simbólico. Tradução de Fernando Tomaz. 4. ed. Rio de Janeiro: Bertrand Brasil, 2001. p. 59-73.

BOURDIEU, Pierre. É possível um ato desinteressado? In: BOURDIEU, Pierre. Razões práticas: sobre a teoria da ação. Tradução de Mariza Corrêa. 3. ed. Campinas: Papirus Editora, 2001. p. 137-156.

BOURDIEU, Pierre. O mercado dos bens simbólicos. In: BOURDIEU, Pierre. As regras da arte: gênese e estrutura do campo literário. Tradução de Maria Lúcia Machado. São Paulo: Companhia das Letras, 1996. p. 162-199.

CANCLINI, Néstor García. Capitais da cultura e cidades globais. In: CANCLINI, Néstor García. A globalização imaginada. Tradução de Sergio Molina. São Paulo: Iluminuras, 2003. p. 153 - 166.

CLANDESTINA. A cidade e os livros. \#1 - Escrever e lançar livro na pandemia, com José Falero [podcast apresentado por Amanda Zulke e Fernando Ramos] Spotify, 7 dez. 2020. 61 min.

COMPANHIA DAS LETRAS. Daniel Galera. Disponível em: $<$ https:// www.companhiadasletras.com.br/autor.php?codigo $=01975>$ Acesso em: 25 jan. 2021. 
COMPANHIA DAS LETRAS. Daniel Pellizzari. Disponível em: $<$ https:// Www.companhiadasletras.com.br/autor.php?codigo $=02576>$ Acesso em: 25 jan. 2021.

COMPANHIA DAS LETRAS. Michel Laub. Disponível em: $<$ https:// Www.companhiadasletras.com.br/autor.php?codigo $=01288>$ Acesso em: 25 jan. 2021.

COMPANHIA DAS LETRAS. Paulo Scott. Disponível em: $<$ https:// www.companhiadasletras.com.br/autor.php?codigo $=03415>$ Acesso em: 25 jan. 2021.

COMPTON-LILLY, Catherine. The Development of Writing Habitus: A Ten-Year Case Study of a Young Writer. Written communication [SAGE], Auburn, v.31(4), p. 371-403, Out. 2014.

DALCASTAGNÉ, Regina. Um território contestado: literatura brasileira contemporânea e as novas vozes sociais. Paris, Iberic@l, n. 2, p. 13 -18, 2012. Disponível em: <http://iberical.paris-sorbonne.fr/wp-content/ uploads/2012/03/002-02.pdf $>$ Acesso em: 26 jul. 2019.

EAGLETON, Terry. Teoria da literatura: uma introdução. Tradução de Waltensir Dutra. 6. ed. São Paulo: Martins Fontes, 2006.

FALERO, José. De volta ao campus. Parêntese, Porto Alegre, 23 jul. 2020. Disponível em: $<$ https://www.matinaljornalismo.com.br/parentese/ jose-falero-de-volta-ao-campus/> Acesso em: 23 dez. 2020.

FALERO, José. Entrevista à autora. [interação virtual síncrona com gravação]. 15 jan. 2021.

FALERO, José. Os supridores. São Paulo: Todavia, 2020.

FALERO, José. Vila Sapo. Porto Alegre: Venas abiertas, 2019.

FERREIRA, Gisele da Silva; MENEZES, Daiane Boelhouwer. Relatório de análise socioeconômica da cidade de Porto Alegre. Porto Alegre: FEE, 2017. GALERA, Daniel. Meia noite e vinte. São Paulo: Companhia das Letras, 2016. IBGE. Síntese de Indicadores Sociais: em 2019, proporção de pobres cai para $24,7 \%$ e extrema pobreza se mantém em $6,5 \%$ da população. Disponível em: $<$ https://agenciadenoticias.ibge.gov.br/agencia-sala-deimprensa/2013-agencia-de-noticias/releases/29431-sintese-de-indicadores- 
sociais-em-2019-proporcao-de-pobres-cai-para-24-7-e-extrema-pobrezase-mantem-em-6-5-da-populacao> Acesso em: 15 jan. 2021.

LAHIRE, Bernard. A transmissão familiar da ordem desigual das coisas. Tradução de Pascoal Carvalho. Sociologia, Porto, vol. XXI, p. 13-22, 2011. LAHIRE, Bernard. Specificity and independence of the literary game. Nationalities Papers, Cambridge, vol. 40, n. 3, p. 411-429, May 2012.

LAHIRE, Bernard; WELLS, Gwendolyn. The Double Life of Writers. New Literary History, Baltimore, vol. 41, n. 2, pp. 443-465, 2010.

LUCCHESE, Alexandre. De servente de pedreiro a escritor: gaúcho José Falero conquista mercado editorial do centro do país. GZH, Porto Alegre, 17 ago. 2020. Disponível em: <https://gauchazh.clicrbs.com. $\mathrm{br} /$ cultura-e-lazer/livros/noticia/2020/08/de-servente-de-pedreiro-aescritor-gaucho-jose-falero-conquista-mercado-editorial-do-centro-dopais-ckdywbjs4003m013gsq56bgkx.html> Acesso em: 31 dez. 2020.

MASSUELA, Amanda. Quem é e sobre o que escreve o autor brasileiro. Entrevista com Regina Dalcastagné. Revista Cult [Eletrônica], São Paulo, 5 fev. 2018. Disponível em: $<$ https://revistacult.uol.com.br/home/queme-e-sobre-o-que-escreve-o-autor-brasileiro/> Acesso em: 20 jan. 2021.

MERCOSUL. Manual pedagógico sobre el uso del lenguaje inclusivo y no sexista. Buenos Aires, IPPDH, 2018. Disponível em: <http://www. ippdh.mercosur.int/pt-br/publicaciones/manual-pedagogico-sobre-o-usoda-linguagem-inclusiva-nao-sexista/> Acesso em: 25 jan. 2021.

MICELI, Sergio. Sonhos da periferia: inteligência argentina e mecenato privado. São Paulo: Todavia, 2018.

PÉCORA, Alcir. 'Os Supridores' diverte pela originalidade de seu 'Marx para manos'. São Paulo, Folha de São Paulo [Ilustrada], 20 nov. 2020. Disponível em: <https://www1.folha.uol.com.br/ilustrada/2020/11/ossupridores-diverte-pela-originalidade-de-seu-marx-para-manos.shtml $>$ Acesso em: 27 jan. 2020.

PNUD Brasil. Ranking IDH Global 2014. Disponível em: <https://www. br.undp.org/content/brazil/pt/home/idh0/rankings/idh-global.html $>$ Acesso em: 20 jan. 2021.

PUCRS. Ato criativo - Luiz Antonio de Assis Brasil e os 35 anos da Oficina de Criação Literária. Porto Alegre, 05 ago. 2020. Disponível 
em: $<$ https://www.pucrs.br/cultura/evento/ato-criativo-luiz-antonio-deassis-brasil-e-os-35-anos-da-oficina-de-criacao-literaria/> Acesso em: 21 jan. 2021.

RIO GRANDE DO SUL. Secretaria de Políticas para as mulheres. Grupo de Trabalho (Dec.Est. $\mathrm{n}^{\circ}$ 49.995/2012). TOLEDO, Leslie Campaner de et al. (Orgs). Manual para uso não sexista da linguagem. Porto Alegre: Secretaria de Comunicação e Inclusão Digital, 2014.

SILVA, Juremir Machado da. Falero, um grande escritor na área. Correio do Povo, Porto Alegre, 10 dez. 2019. Disponível em: <https://www. correiodopovo.com.br/blogs/juremirmachado/falero-um-grande-escritorna-\%C3\%A1rea-1.385841> Acesso em: 25 jan. 2021.

SPERB, Paula. Renascentista da quebrada, José Falero faz literatura que vai de Machado a Tarantino. Folha de São Paulo [Ilustrada], São Paulo, 1 jan. 2021. Disponível em: <https://www1.folha.uol.com.br/ ilustrada/2021/01/renascentista-da-quebrada-jose-falero-faz-literaturaque-vai-de-machado-a-tarantino.shtml $>$ Acesso em: 1 jan. 2021.

WIKIPEDIA. Daniel Galera. Disponível em: $<$ https://pt.wikipedia.org/ wiki/Daniel_Galera> Acesso em: 25 jan. 2021.

WIKIPEDIA. Paulo Scott. Disponível em: $<$ https://pt.wikipedia.org/wiki/ Paulo_Scott $>$ Acesso em: 25 jan. 2021.

Recebido em: 29 de janeiro de 2021.

Aprovado em: 5 de julho de 2021. 